\title{
Design of Linear Plasma Position Controllers with Intelligent Feedback Systems for Aditya Tokamak
}

\author{
Femila Roseline J, N. M. Nandhitha \\ Sathyabama Institute of Science and Technology, Jeppiaar Nagar, Old Mahabalipuram Road, India
}

\begin{tabular}{|c|c|}
\hline Article Info & ABSTRACT \\
\hline Article history: & order to increase the performance of Aditya tokamak, it is necessary to \\
\hline Received Nov 28, 2017 & $\begin{array}{l}\text { determine the feedback coil current for positioning the plasma within the } \\
\text { magnetic chamber. In this paper, transfer functions are obtained for the }\end{array}$ \\
\hline Revised Jan 8, 2018 & plasma position prediction system. Four different feedback controllers are \\
\hline Accepted Apr 19, 2018 & $\begin{array}{l}\text { developed to improve the performance of the prediction system. From the } \\
\text { analysis, Neural Network controller does not have overshoot while the PID }\end{array}$ \\
\hline eyword: & \\
\hline
\end{tabular}

Back propagation network

Fuzzy logic controller

Neural network

PID controller

Plasma position

Copyright (C) 2018 Institute of Advanced Engineering and Science. All rights reserved.

\section{Corresponding Author:}

Femila Roseline J.,

Department of Electrical and Electronics Engineering,

Sathyabama Institute of Science and Technology,

Jeppiaar Nagar, Old Mahabalipuram Road, Chennai 600 119, Tamil Nadu, India.

Email: femila14@gmail.com

\section{INTRODUCTION}

Aditya tokamak is a fusion reactor that uses thermonuclear fusion for the generation of power. The principle behind the generator is as follows: At high temperatures, Hydrogen ions combine to form plasma which is confined within the magnetic chamber. Amount of power generated is dependent on the time duration for which the plasma is confined within the chamber without hitting the in-vessel components. Hence it is necessary to confine the palsma within the chamber for a long duration of time. In order to develop a corrective system for the confinement of plasma, it is necesaary to predict the position of the plasma. Considerable research is carried out in this area. Conventionally SISO and MIMO systems were used for plasma position prediction. Also linear controllers for plasma position prediction were developed.

R. Ambrosino et al 2015 [1] developed a control system to operate the plasma for the entire pulse for ITER tokamak. This control scheme consisted of four controllers namely current decoupling controller, the vertical stabilization controller, the plasma current controller and the shape controller. Justin E. Barton et al 2015 [2] developed an integrated feedback algorithm for plasma current and electron temperature profile control in TCV tokamak. Performance of the integrated profile controller was studied by tracking a nominal target, and then by modulating the electron temperature profile between equilibrium points while maintaining the current profile in a stationary condition. However closed loop plasma state observer was not developed. Paolo Bettini et al 2015 [3] used two numerical codes (CAFE [4], CARIDDI) to control the characteristics (response) of the magnetohydrodynamic in the large JT-60SA fusion device. These codes were based on alternative edge element formulations (discrete and integral, respectively) for 3-D eddy current computation. William Wehner et al 2015 [5] had proposed a model based approach for the combined regulation of the plasma toroidal angular rotation profile and stored energy for the DIII-D tokamak. 
A control oriented model of the toroidal rotation profile evolution was considered. In order to regulate the profile around the target, they had used an optimal state feedback control. Sundarapandian Vaidyanathan 2015 [6] had discussed the adaptive control of the Tokamak chaotic system with unknown system parameters. Ding Yonghua et al 2013 [7] developed a Back Propagation Neural Network to predict the disruptions caused by locked modes in J-TEXT tokamak. Mirnov coils and locked mode coils signals were used as input data. The network predicted the signal for locked mode. Once intrinsic locked mode disruptions and resonant magnetic perturbation occured, the network would give a prewarning signal. Femila Roseline et al 2015 [8] developed a fuzzy logic based plasma position controller in aditya tokamak. Totally seven, nine and eleven membership functions were used for different shape of the membership functions. And evident that nine membership functions with triangular shape would provide the better results.

Du et al 2014 [9] developed a Hopfield neural network for a system to optimize the values of PID in real time. As the PID controller could not control the performance of the complex industrial process, a Hopfield neural net was developed by using Hebb rules. Hebb rules used to identify the parameters of the system. The performance index has been improved greatly. Feng et al 2017 [10] derived a mathematical model of erection mechanism and described an application of fuzzy logic based adaptive PID controller in erection system. The erection angle controlled by fuzzy logic, PID and fuzzy adaptive PID controllers were compared in simulation using Simulink in MATLAB and also in real time. Mounir et al 2016 [4] proposed the combination of sliding mode control with the performance of fuzzy logic in photovoltaic system. In first half 25 rules were used with two input in fuzzy logic controller and in the second part the gain was adjusted in online for the switching controllers. From the literaturees, is found that either linear controllers or intelligent non-linear controlers are used. A combination of these techniques is not yet explored to develop the plasma position systems.

Hence in this paper, a hybrid technique that uses an intelligent controller for fine tuning the proposed linear system is developed. This paper is organized as follows: The proposed methodology is described in Section 2. In this section, PID based plasma position controller, fuzzy logic based plasma position controller and neural network based plasma position controller in plasma position control are explained. Section 3 compares the results of all the controllers and section 4 concludes the work.

\section{RESEARCH METHODOLOGY}

Acquired database consists of radial and vertical positions of plasma, plasma current and feedback coil current. First three parameters can be used as input parameters for predicting the fourth parameter. However the impact of vertical position is less than the other two input parameters. Hence in this work, radial position and plasma current are used for developing a system to predict the feedback coil current. Data normalization is performed to meet the specifications in developing the transfer functions of the proposed system. After developing the transfer functions, the system is fine tuned with PID controller, Fuzzy Logic Controller (FLC) and Neural Network (NN) controller at the feedback. Also to further improve the performance of the NN controller, the initial weights of NN are optimized using Genetic Algorithm (GA).

\subsection{PID Based Plasma Position Controller}

In order to validate the proposed system, it is simulated using SIMULINK toolbox in MATLAB and a step input is given to the system. Though the expected output is also a step waveform, the actual output is different. Hence it is necessary to fine tune the proposed transfer function through a closed loop control. Initially a PID controller is used at the feedback and is shown in Figure 1.

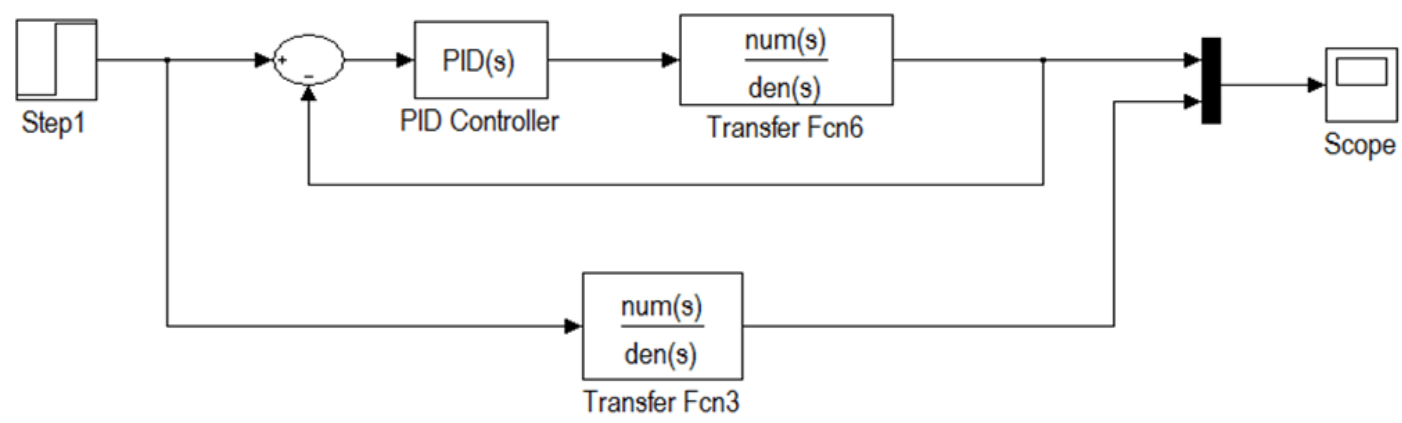

Figure 1. Open loop and PID based plasma position controller 
The system constants are tuned automatically for providing the step output for the given set of transfer functions. Though the output signal resembles the step waveform, an undesirable overshoot is also present as seen in Figure 2. Hence it is necessary to identify the feedback controller that considers the dataset for its parameter design, so as to reduce the overshoot.

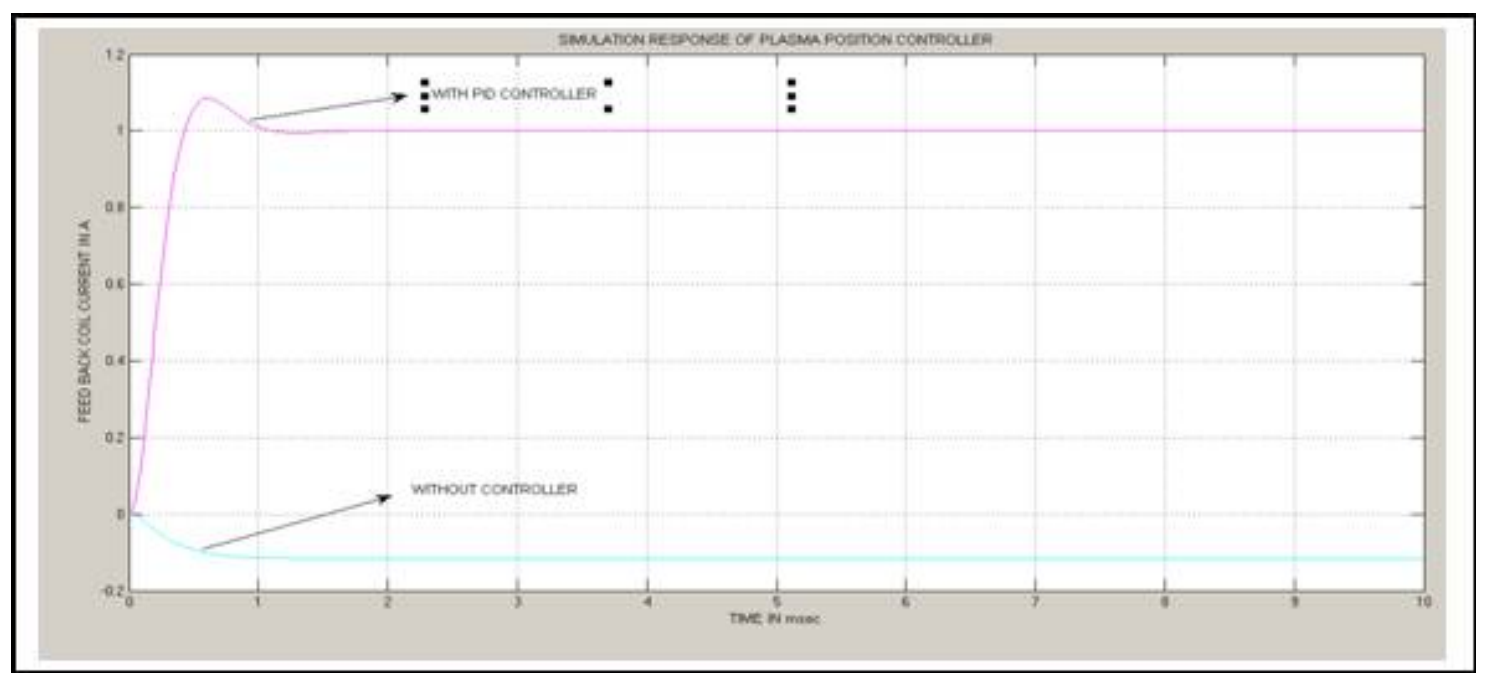

Figure 2. Simulation response of open loop and PID based plasma position controller

\subsection{Fuzzy Based Plasma Position Controller}

In an attempt to reduce the overshoot, FLC is used at the feedback as shown in Figure 3 . The proposed FLC uses triangular membership function with seven levels as it provides better prediction [8]. From the Figure 4, the overshoot is removed. Even though the peak over shoot is reduced, the settling time of the FLC feedback is much higher than that of the PID based plasma position controller. In order to reduce the settling time and fine tune the network, $\mathrm{NN}$ controller is used at the feedback to fine tune the network.

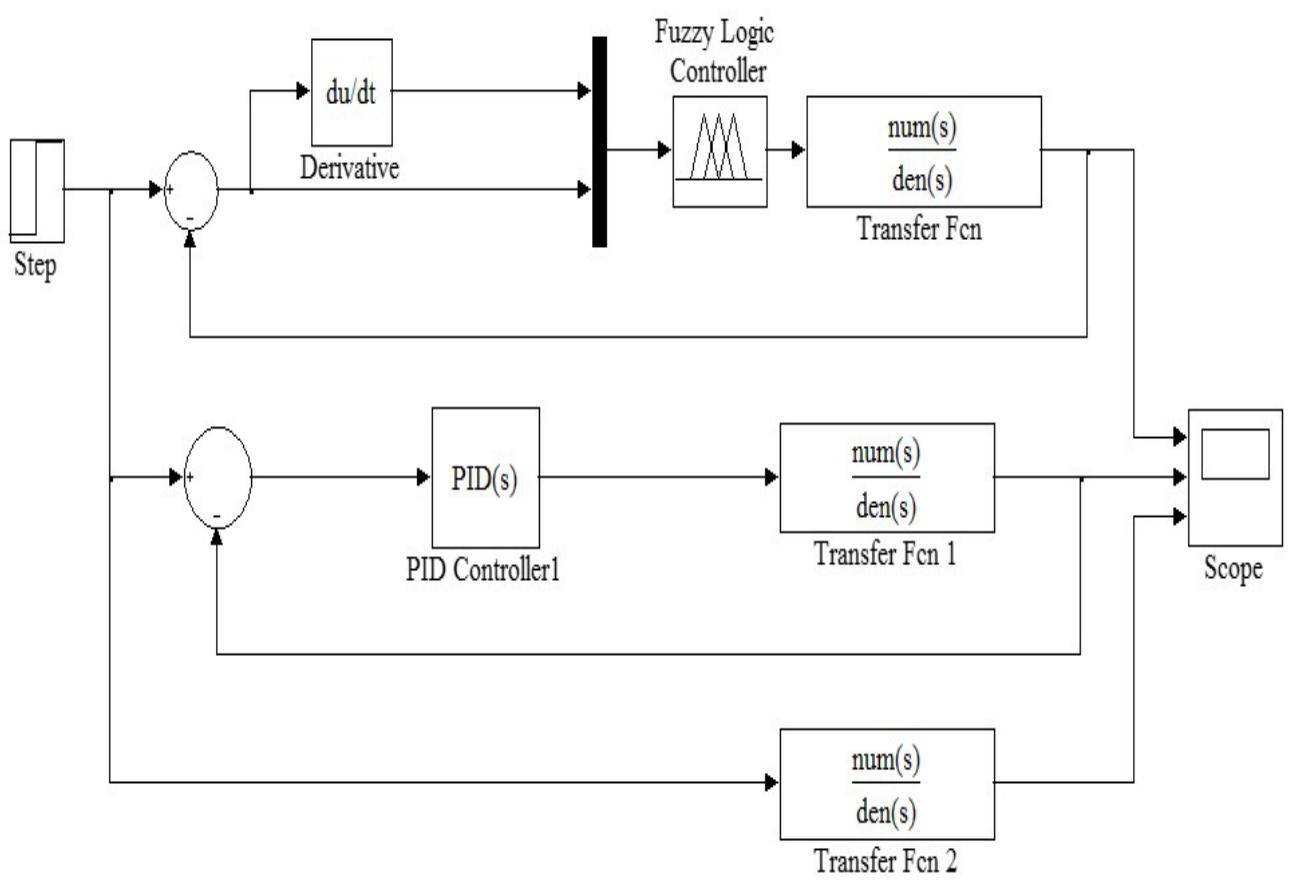

Figure 3. Simulation diagram of open loop and PID and fuzzy based plasma position controller 


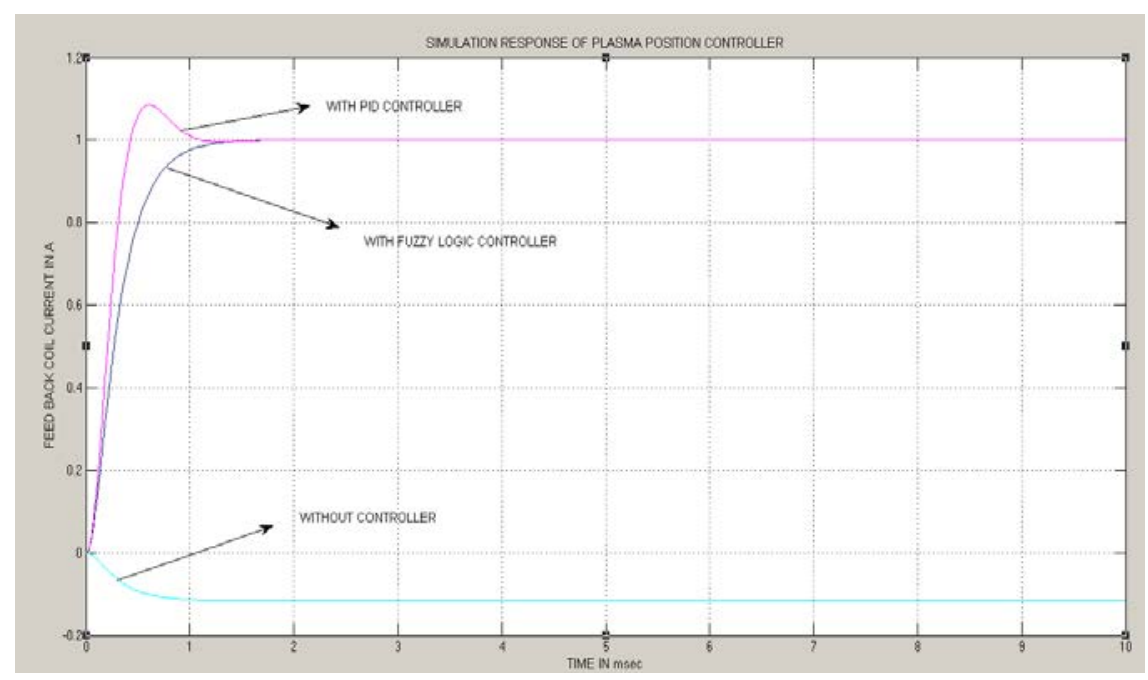

Figure 4. Simulation response of open loop and PID and Fuzzy logic based plasma position controller

\subsection{Neural Network Based Plasma Position Controller}

The proposed Back Propagation Network (BPN) used for tuning the plasma position controller has one hidden layer with ten neurons as shown in Figure 5. From the dataset, $70 \%$ of the data was selected for training purpose. $15 \%$ of the data was selected for validation and the remaining $15 \%$ of the data was selected for testing the network. Proposed Neural Network Controller trained with 102 epochs used at the feedback is shown in Figure 6. From Figure 7, it is evident that the settling time of the BPN based plasma position controller is lesser than that of the fuzzy based system. However in order to improve the performance further it is necessary to optimize the weight functions of BPN.a

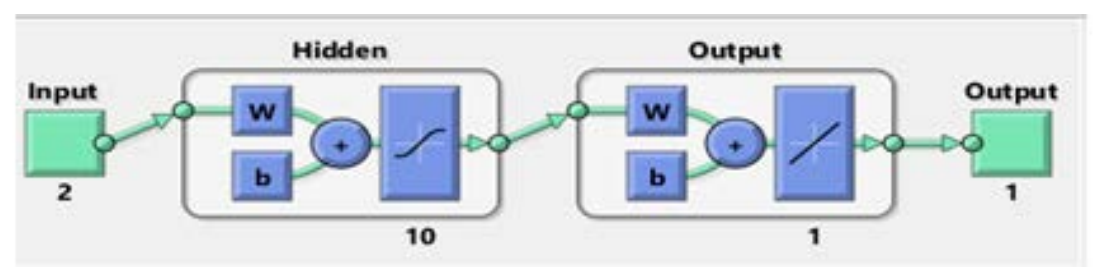

Figure 5. Architecture of BPN

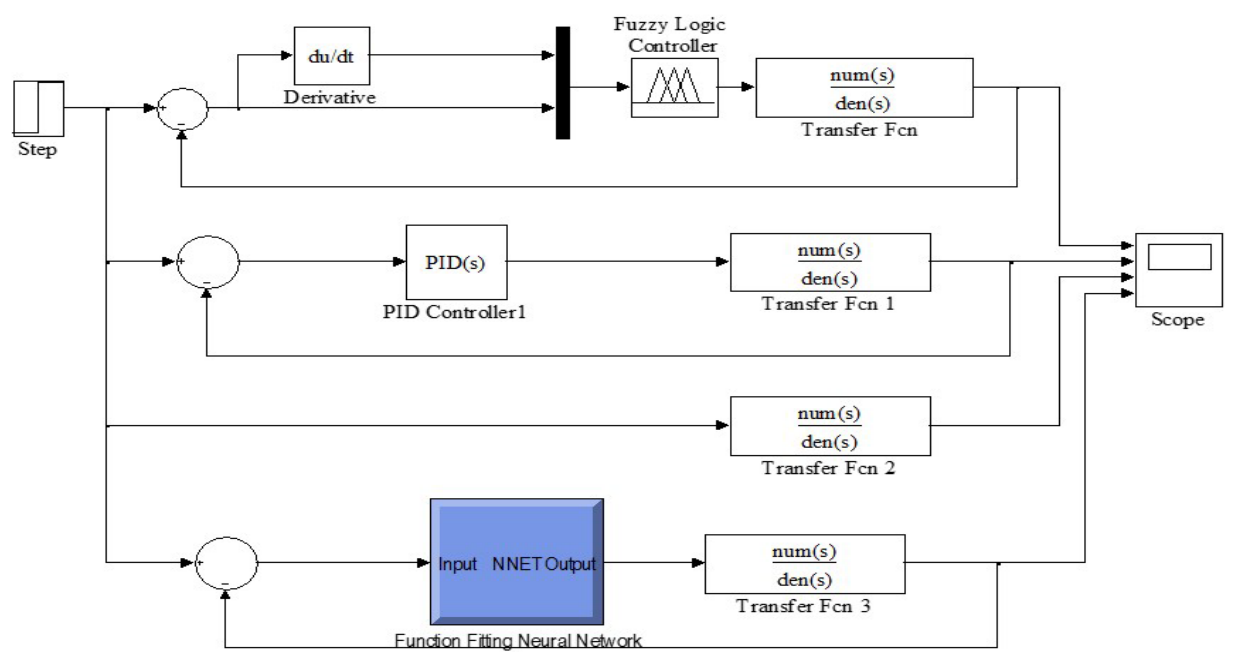

Figure 6. Simulation model of BPN based plasma position controller 


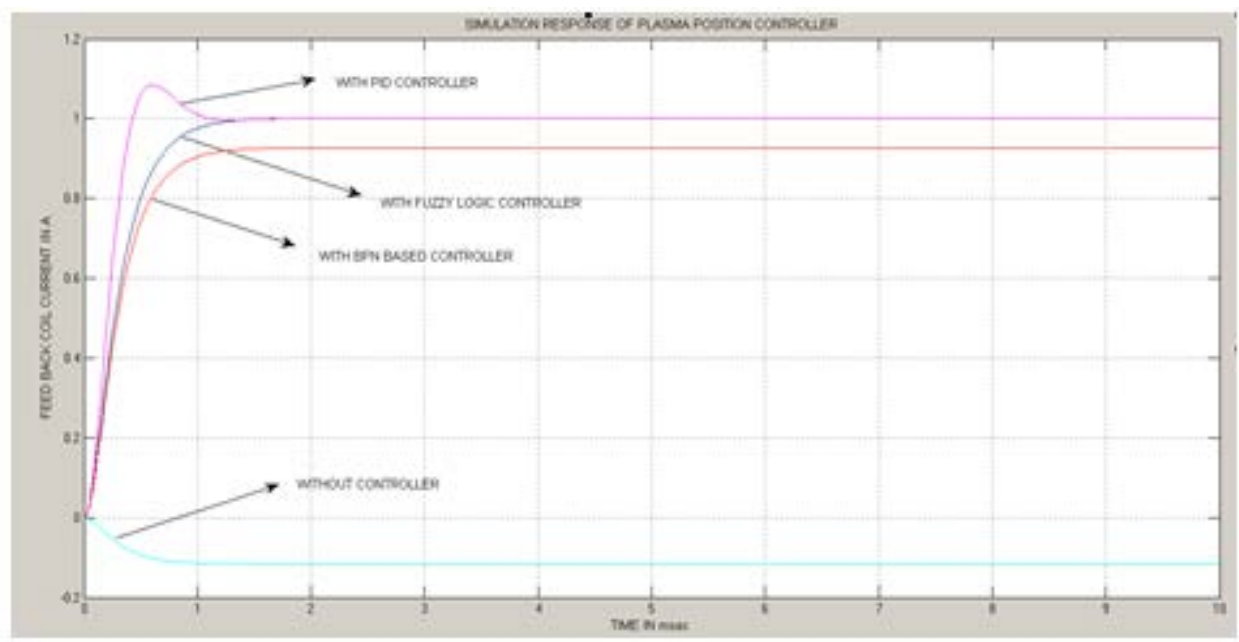

Figure 7. Simulation response of open loop and PID and Fuzzy logic and BPN based plasma position controller

\section{RESULTS AND ANALYSIS}

The performance metrics of PID controller, Fuzzy logic controller and BPN based controller are tabulated in Table 1. From the Table 1, the delay time is less and rise time is more for the case of BPN based controllers. Peak time is less for PID controller. It shows that the peak overshoot of the PID controller is more than the other controllers. Even though there is no peak overshoot in Fuzzy logic controller, the settling time is more than the PID controller. The settling time is further reduced by designing the BPN based controller. At last it is evident that the Steady state error is less for the case of BPN based controller.

Table 1. Performance Metrics

\begin{tabular}{ccccccc}
\hline Measuring Parameters & $\begin{array}{c}\text { Delay Time } \\
(\mathrm{msec})\end{array}$ & $\begin{array}{c}\text { Rise Time } \\
(\mathrm{msec})\end{array}$ & $\begin{array}{c}\text { Peak Time } \\
(\mathrm{msec})\end{array}$ & $\begin{array}{c}\text { Settling Time } \\
(\mathrm{msec})\end{array}$ & $\begin{array}{c}\text { Maximum Peak } \\
\text { Overshoot }\end{array}$ & $\begin{array}{c}\text { Steady State } \\
\text { Error }\end{array}$ \\
\hline PID Controller & 0.27 & 0.36 & 0.61 & 0.90 & 1.08 & 0.05 \\
Fuzzy Logic Controller & 0.25 & 0.65 & 1.21 & 1.20 & 0.90 & 0.04 \\
BPN based controller & 0.24 & 0.95 & 1.02 & 1.00 & 0.80 & 0.02 \\
\hline
\end{tabular}

\section{CONCLUSION}

In this paper, a set of transfer functions were developed for plasma position prediction from the given dataset. Also in order to fine tune the system, PID controller, fuzzy controller and neural network controller were used. PID controller had a faster settling time. But the output had an undesirable overshoot. Fuzzy based and neural controllers did not have the overshoot. But the compromise was made in the settling time. The vertical position of the plasma was not considered for predicting the plasma. This modification can be included to further improve the performance of the network.

\section{ACKNOWLEDGEMENTS}

This research work is partly funded by the Board of Research in Fusion Science and Technology (BRFST), India NFP-ELE-A11-03. The authors would like to acknowledge the support received from BRFST, India and Sathyabama University, Chennai for the research activities pertaining to this article.

\section{REFERENCES}

[1] R. Ambrosino, et al., "Design and non linear validation of the ITER magnetic," 2015 IEEE Conference on Control Applications (CCA),Part of 2015 IEEE Multi-Conference on Systems and Control, Sydney, Australia, pp. 12911295, 2015.

[2] J. E. Barton, et al., "Simultaneous Closed-loop Control of the Current Profile and the Electron Temperature Profile in the TCV Tokamak,” 2015 American Control Conference, Palmer House Hilton, Chicago, IL, USA, pp. 33163321, 2015. 
[3] P. Bettini, et al., "Advanced Computational Tools for the Characterization of the Dynamic Response of MHD Control Systems in Large Fusion Devices,” IEEE Transactions on Magnetics, vol/issue: 51(3), pp. 7204105, 2015.

[4] M. Derri, et al., "Fuzzy Sliding Mode Control for Photovoltaic System," International Journal of Power Electronics and Drive System (IJPEDS), vol/issue: 7(3), pp. 964-973, 2016.

[5] W. Wehner, et al., "Toroidal Rotation Profile Control for the DIII-D Tokamak," 2015 American Control Conference Palmer House Hilton, Chicago, IL, USA, pp. 3364-3369 2015.

[6] S. Vaidyanathan, "Dynamics and Control of Tokamak System with Symmetric and Magnetically Confined Plasma," International Journal of ChemTech Research CODEN (USA): IJCRGG, vol/issue: 8(6), pp. 795-803, 2015

[7] J. X. Ding, et al., "Neural Network Prediction of Disruptions Caused by Locked Modes on J-TEXT Tokamak," Plasma Science and Technology, vol/issue: 15(11), 2013.

[8] J. F. Roseline and N. M. Nandhitha, "Design of Fuzzy Logic based Plasma Position Control in Aditya Tokamak," Indian Journal of Science and Technology, vol/issue: 8(12), pp. 1-7, 2015.

[9] W. Du, et al., "The Design of PID Controller Based On Hopfield Neural Network,” TELKOMINKA Indinesian journal of Electrical Engineering, vol/issue: 12(4), 2014.

[10] F. Jiangtao, et al., "Mathematical Modeling and Fuzzy Adaptive PID Control of Erection Mechanism," TELKOMNIKA, vol/issue: 15(1), pp. 254-263, 2017.

\section{BIOGRAPHIES OF AUTHORS}

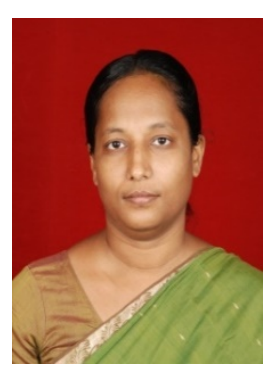

Femila Roseline Jayapaul received the B.E. degree in Electrical and Electronics engineering from Madurai Kamaraj University, Madurai, India, in 1997, and the M.E. degree in Power Electronics and Industrial Drives from Sathyaba`ma University, Chennai, India, in 2004. Currently she is Assistant Professor in the Department of Electrical and Electronics Engineering, Sathyabama University, Chennai. She has eleven years of teaching experience. Her current research interests include power electronics, fuzzy logic and neural networks. Ms. Jayapaul is a member of the Institution of Electrical and Electronics Engineers (IEEE).

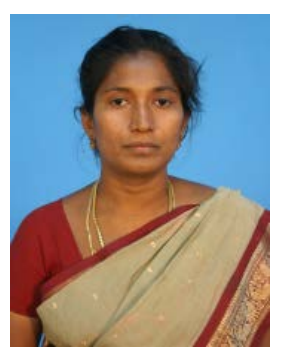

Dr. N. M. Nandhitha is currently working in the Department of Electronics and TeleCommunication Engineering in Sathyabama University. She has graduated from Government College of Technology, Coimbatore in Electronics and Communication Engineering. She has completed Post Graduation in Power Electronics and Industrial Drives with gold medal. She completed her Ph.D. in Development of wavelet based tools and NeuroFuzzy control software for on-line weld Monitoring by Thermal Imaging, a project sponsored by IGCAR, Kalpakkam. She is also co-investigator in research projects sponsored by DST, IPR, BRFST, BRNS to Sathyabama University. 